DOI: http://dx.doi.org/10.18203/2320-6012.ijrms20190350

\title{
Retraction
}

The article titled, "Prevalence of refractive errors and corneal topographic changes in unilateral congenital ptosis vs the fellow eye: a clinical study", published in the International Journal of Research in Medical Sciences, Volume 7, Issue 2, 2019, Pages 442-446, DOI: http://dx.doi.org/10.18203/2320-6012.ijrms20190350 is being retracted due to authorship dispute. 


\title{
Original Research Article
}

\section{Prevalence of refractive errors and corneal topographic changes in unilateral congenital ptosis vs the fellow eye: a clinical study}

\author{
Nitin V. Vichare* \\ Department of Ophthalmology, Army Command Hospital (WC), Chandigarh, Haryana, India
}

Received: 03 December 2018

Accepted: 29 December 2018

\section{*Correspondence:}

Dr. Nitin V. Vichare,

E-mail: vicharenitin@yahoo.com

Copyright: $($ ) the author(s), publisher and licensee Medip Academy. This is an open-access article distributed under the terms of the Creative Commons Attribution Non-Commercial License, which permits unrestricted non-commercial use, distribution, and reproduction in any medium, provided the original work is properly cited.

\section{ABSTRACT}

Background: This study was undertaken to assess the effect of upper eyelid pressure on refractive errors and corneal topography in eyes with ptosis and compare it with fellow normal eyes.

Methods: This cross-sectional observational study involved 83 patients with unilateral congenital ptosis. Evaluation of ptosis done to classify it into mild, moderate and severe. Manual refraction and corneal topography done to obtain refractive errors, astigmatism, keratometric data and topographic patterns. These values in eyes with ptosis were compared with that in fellow nonptotic eyes.

Results: Around $21.69 \%$ participants had mild ptosis, $36.14 \%$ had moderate and $42.17 \%$ had severe ptosis. $19.28 \%$ eyes with ptosis were myopic as compared to $12.05 \%$ eyes without ptosis. $16.86 \%$ eyes with ptosis had hyperopia as compared to $2.41 \%$ normal eyes. $45.78 \%$ eyes with ptosis had significant refractive astigmatism compared to $6.02 \%$ fellow eyes. $57.83 \%$ of eyes with ptosis had significant Sim K astigmatism as compared to $28.92 \%$ normal eyes. The prevalence of refractive errors increased with the severity of ptosis. Majority of eyes with ptosis $(53.01 \%)$ had symmetrical bow tie pattern compared to round pattern seen in most of the normal eyes (39.76\%).

Conclusions: Upper eyelid pressure in ptosis causes significant refractive and corneal topographic changes. The greater prevalence of Sim K astigmatism $(57.83 \%)$ than refractive astigmatism $(45.78 \%)$ underlines the need of corneal topography in all cases to ensure timely detection of astigmatism and institution of proper corrective measures to prevent development of amblyopia.

Keywords: Astigmatism, Corneal topography, Congenital ptosis, Refractive error

\section{INTRODUCTION}

The term ptosis typically implies droopiness of the upper eyelid. ${ }^{1}$ Ptosis can be congenital or acquired. Congenital ptosis is due to a developmental dystrophy of the levator muscle. Acquired ptosis can be neurogenic, myogenic, traumatic or mechanical. ${ }^{2}$ Normal upper eyelid which covers upper 2 millimetre $(\mathrm{mm})$ of cornea is known to induce static pressure on the ocular surface and causes cornea to assume its typically with-the-rule astigmatic shape. ${ }^{3,4}$ Drooping upper eyelid in ptosis can lead to significant refractive errors, corneal topographic changes and induced astigmatism. ${ }^{5}$ In fact, the most common refractive error seen in ptosis is astigmatism. ${ }^{6,7}$ The topographic changes seen in congenital ptosis are more asymmetric and irregular with clinically significant astigmatism. ${ }^{5}$ Most studies measure refractive errors in patients with ptosis, however comparison is made with normal subjects. ${ }^{6-8}$ This does not explain the effect of ptosis on eyes in a patient when extent of ptosis differs in both eyes. This study was undertaken to investigate association between severity of ptosis and the occurrence 
of corneal topographic changes and refractive errors in unilateral congenital ptosis as compared to the fellow non ptotic eye.

\section{METHODS}

This was a cross-sectional analytical study carried out over a period of two years at an eye department of a tertiary care hospital. The study participants were the consecutive patients of unilateral congenital ptosis attending the outpatient clinics of the eye department. All patients with ptosis other than congenital ptosis like traumatic ptosis, myogenic ptosis or aponeurotic ptosis were excluded. Similarly, patients with visual disturbance due to congenital cataract, congenital glaucoma, optic atrophy, corneal opacities, previous history of ocular surgery and patients unwilling to give consent were also excluded from the study.

The sample size was calculated by using prevalence of refractive errors in eyes with ptosis as $37.04 \%$ and that in normal eyes as $18 \%$ (values taken from previous study). ${ }^{5}$ The sample size was calculated by using $5 \%$ level of significance and $80 \%$ power. Eighty three participants were found optimal for the study. Institutional ethical clearance was taken for the conduct of the study and the study complied with the tenets of the Declaration of Helsinki. The written informed consent was taken from all the patients.

All the patients were examined by the same examiner. A brief ocular and medical history was taken. Visual acuity was assessed by Snellen's chart for patients $>5 \mathrm{yrs}$ of age and by Picture chart or Tumbling E-chart for children $<5$ yrs of age. A detailed slit lamp examination and fundus examination with direct and indirect ophthalmoscope were performed. Complete evaluation of ptosis including measurement of margin reflex distance 1 and 2 (MRD1 and MRD 2), Margin limbal distance (MLD), levator muscle Function was done by using ruler and torchlight. Cycloplegic refraction was done for all patients and was recorded in spherical equivalent (SE) notation. Children $<5$ years of age were given eye ointment atropine $1 \% \mathrm{BD}$ for 3 days and were examined on the fourth day. Patients $>5$ years of age were examined on the same day after instilling eye drop cyclopentolate 1\% 3-4 times every 15 minutes. Corneal topography was done on placido disc based corneal topographer PCT-200 by Optopol (Figure 1) to obtain $\operatorname{Sim} K$ values and astigmatism. Sim $K$ provides the power and the location of the steepest meridian and the meridian $90^{\circ}$ away. ${ }^{5}$

The corneas on topographs were classified according to a qualitative classification method described previously. ${ }^{9}$ All the topographs were classified on the basis of the configuration of the predominant pattern seen on the map. As a result, five types of corneal topographic patterns were defined: round, oval, symmetric bow tie, asymmetric bow tie and irregular as described by Bogan SJ et al. ${ }^{9}$

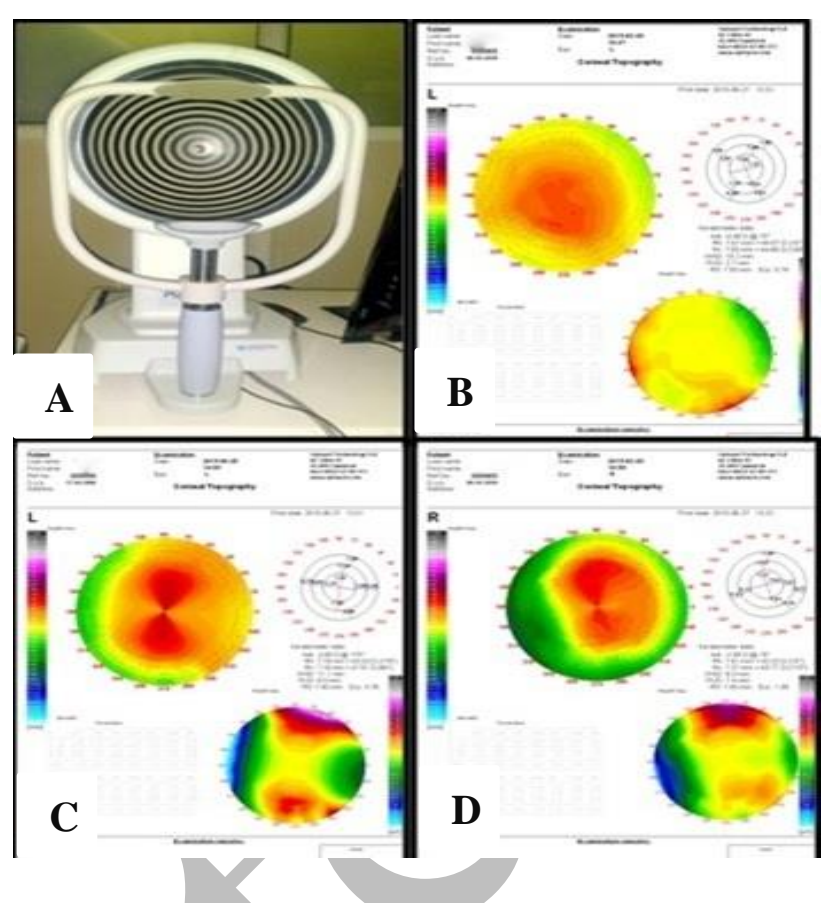

Figure 1: Corneal topography. A) Placido disc based corneal topographer PCT-200 by optopol and, B, C, D) Topography maps showing various patterns.

SE was calculated by adding half of the cylindrical value to the spherical value of the refractive error $[\mathrm{SE}=$ Spherical value + [cylindrical value/2] (in diopters)]. SE of $\leq-0.5 \mathrm{D}$ was considered as myopia, $\mathrm{SE} \geq+1 \mathrm{D}$ as Hyperopia and astigmatism was considered significant if its magnitude was $\geq 1 \mathrm{D}$. $^{10,11}$ Astigmatism obtained from refraction was termed as refractive astigmatism. Ametropia was defined as absence of emmetropia i.e. SE $<-0.5$ or $>+1$ D. MRD 1 was measured in $\mathrm{mm}$ as distance from corneal light reflex to the centre of upper lid margin with patient's eye in the primary position of gaze. If no reflex is visible, the eyelid is raised till corneal light reflex visible and the number is recorded as a negative number. Value of normal MRD1 is $4 \mathrm{~mm} .^{2}$ Ptosis was graded according to MRD1 values as mild if between 4 to $2 \mathrm{~mm}$, moderate if $1 \mathrm{~mm}$ and severe if $\leq 0 \mathrm{~mm}$. Levator function measured in $\mathrm{mm}$ as eyelid excursion from extreme downgaze to extreme upgaze.

\section{Statistical analysis}

Statistical analysis was performed by using SPSS (Statistical package for social sciences) version 20.0. Comparisons were performed using Chi-square test, ANOVA, or Fisher's exact test. A P value $\leq 0.05$ was considered statistically significant.

\section{RESULTS}

The study included 83 eyes of 83 patients with unilateral congenital ptosis. 83 fellow eyes without ptosis served as controls. There was equal sex distribution in study population with $42(50.60 \%)$ males and $41(49.40 \%)$ females. The majority of the patients were $<30$ years of 
age with mean age of the patients being 16.52 \pm 12.59 years. Visual acuity in eyes with ptosis was compared with that of fellow normal eye (Table 1). Visual acuities differed significantly in ptosis and non-ptosis group with ptotic eyes having less visual acuity ( $\mathrm{P}$ value $<0.001$ ). Out of 83 patients, $18(21.69 \%)$ patients had mild ptosis,
$30(36.14 \%)$ patients had moderate ptosis while 35 $(42.17 \%)$ patients had severe ptosis. There was significant association between decreased visual acuity and severity of ptosis. It was observed that eyes with more severe ptosis had poorer visual acuities (Fisher's exact test, P-value=0.001) (Table 2).

Table 1: Comparison between ptotic eye with the fellow eye.

\begin{tabular}{|llll|}
\hline & Ptotic eye & Fellow eye & P-value \\
\hline Number of eyes & 83 & 83 & \\
\hline Visual Acuity & & & \\
\hline$\geq 6 / 12$ & $51(61.45 \%)$ & $71(85.54 \%)$ & $<0.001$ \\
\hline $6 / 18-6 / 36$ & $23(27.71 \%)$ & $5(6.02 \%)$ & \\
\hline$\leq 6 / 60$ & $9(10.84 \%)$ & $7(8.44 \%)$ & \\
\hline Refractive error type & & & 0.001 \\
\hline Myopia & $16(19.28 \%)$ & $10(12.05 \%)$ & \\
\hline Astigmatism & $20(24.09 \%)$ & $2(2.4 \%)$ & $<0.001$ \\
\hline Hypermetropia & $14(16.86 \%)$ & $2(2.41 \%)$ & \\
\hline Refractive astigmatism (Mean \pm SD) & $0.880 \pm 0.662$ & $0.449 \pm 0.602$ & \\
\hline Sim K Astigmatism (Mean \pm SD) & $1.278 \pm 0.656$ & $0.871 \pm 0.426$ & \\
\hline Corneal Topographic pattern $($ number $\%)$ & & \\
\hline Bow-tie & $55(66.26)$ & $27(32.53)$ & \\
\hline Irregular & $8(9.65)$ & $3(3.61)$ & \\
\hline Oval & $11(13.25)$ & $20(24.10)$ & \\
\hline Round & $9(10.84)$ & $33(39.76)$ & \\
\hline
\end{tabular}

Table 2: Comparison between astigmatism, topography pattern and severity of ptosis.

\begin{tabular}{|llllll|}
\hline & No ptosis & Mild ptosis & Moderate ptosis & Severe ptosis & P-value \\
\hline Number of eyes & 83 & 18 & 30 & 35 & \\
\hline Refractive Astigmatism (Mean \pm SD) & $0.45 \pm 0.60$ & $0.51 \pm 0.41$ & $0.78 \pm 0.44$ & $1.16 \pm 0.81$ & $<0.001$ \\
\hline Sim K Astigmatism (Mean \pm SD) & $0.87 \pm 0.43$ & $0.95 \pm 0.68$ & $1.21 \pm 0.52$ & $1.50 \pm 0.68$ & $<0.001$ \\
\hline Corneal topographic pattern & & & & & \\
\hline Bow-tie & $27(32.5)$ & $7(38.9)$ & $23(76.7)$ & $25(71.4)$ & \\
\hline Irregular & $3(3.6)$ & $2(11.1)$ & $1(3.3)$ & $5(14.3)$ & $<0.001$ \\
\hline Oval & $20(24.1)$ & $4(22.2)$ & $3(10)$ & $4(11.4)$ & \\
\hline Round & $33(39.8)$ & $5(27.8)$ & $3(10)$ & $1(2.9)$ & \\
\hline
\end{tabular}

\section{Refractive errors}

Out of 83 eyes with ptosis, 16 eyes (19.28\%) had myopia, 14 eyes $(16.86 \%)$ had hypermetropia and astigmatism in 20 eyes $(24.09 \%)$. The prevalence of these refractive errors was significantly more in eyes with ptosis when compared with normal fellow eyes (Table 1).

The mean refractive astigmatism in eyes with ptosis was $0.880 \pm 0.662 \mathrm{D}$ while mean refractive astigmatism in normal fellow eyes was $0.449 \pm 0.602 \mathrm{D}$. The astigmatism and severity of ptosis correlated positively with increased magnitude of astigmatism seen with increase in severity of ptosis (ANOVA test, $\mathrm{P}$ value $<0.001$ ) (Table 2).
Out of 38 eyes with ptosis having significant astigmatism, 8 eyes had myopia $\geq-0.5 \mathrm{D}$ and 10 eyes had hyperopia $\geq+1$ D. So actually 50 eyes out of 83 eyes with ptosis had refractive errors (16 eyes with myopia, 14 eyes with hyperopia and 20 eyes with astigmatism). Therefore, the actual prevalence of refractive errors in eyes with ptosis was $60.24 \%$ with emmetropia seen in $39.76 \%$ eyes. Out of 38 eyes with ptosis having significant astigmatism, 20 eyes had myopic astigmatism, 13 eyes had hypermetropic astigmatism and 5 eyes had mixed astigmatism.16.87\% of normal fellow eyes had refractive errors (Table 1). The mean Sim K astigmatism in eyes with ptosis was $1.278 \pm 0.656$ D. The mean Sim K astigmatism in normal fellow eyes was $0.871 \pm 0.426 \mathrm{D}$. The prevalence of $\mathrm{Sim} \mathrm{K}$ astigmatism $>1 \mathrm{D}$ was 
significantly more in ptosis group with 48 eyes $(57.83 \%)$ as compared to $24(28.92 \%)$ normal fellow eyes.

\section{Corneal topographic patterns}

The majority of the eyes with ptosis had bow tie pattern (66.26\%) on topography as compared to normal fellow eyes, which showed round pattern $(39.76 \%)$ as the most common pattern on topography. The prevalence of bow tie pattern in eyes with ptosis was $66.26 \%$ which was significantly more than normal fellow eyes (32.53\%). The round and oval pattern was seen in 20 eyes $(24.09 \%)$ with ptosis while 53 normal fellow eyes $(63.86 \%)$ had round and oval pattern. The frequency of bow tie pattern on corneal topography increased with increase in the severity of ptosis.

\section{DISCUSSION}

Our study had equal distribution of males and females. This may be because there is relatively similar incidence of ptosis in both sexes. This is in accordance with the Indian study by PV NK et al in which study population had $56 \%$ males and $44 \%$ females. ${ }^{6}$ In this study $91.57 \%$ patients were under 30 years of age and $63.85 \%$ patients under 20 years of age. PV NK et al, in a study on refractive errors in congenital ptosis reported similar age distribution with $67.27 \%$ subjects under 20 years of age. ${ }^{6}$ Similarly, in a study conducted by Bavishi AK $51 \%$ study subjects presented between 11 to 20 years of age. ${ }^{12}$ The mean age of the subjects in the present study was $16.52 \pm 12.59$ years which is in accordance with the study by Huo $\mathrm{L}$ et al on form deprivation amblyopia in unilateral congenital ptosis in which mean age of patients was 16.83 years. ${ }^{13} \mathrm{We}$ noticed higher prevalence of severe ptosis $(42.17 \%)$ compared to other studies which reported lower incidence of severe ptosis. ${ }^{13}$ The higher prevalence of severe ptosis in our study could be attributed to relatively late presentation to the ophthalmologist and the low level of awareness in our population.

Comparatively poor visual acuity seen in eyes with ptosis can be attributed to the occurrence of more refractive errors in ptosis. Significantly reduced the visual acuity was noted with an increase in the severity of ptosis. This finding is in accordance with the study by Kumar DA et al on the effect of unilateral congenital ptosis on ocular higher order aberrations which stated that eyes with severe ptosis having low MRD had poor vision. ${ }^{14}$ A study on refractive error, strabismus and amblyopia in congenital ptosis by Thapa $\mathrm{R}$ reported $25 \%$ patients of congenital ptosis with visual acuity less than $6 / 18 .^{7}$ The higher number of eyes with visual acuity $<6 / 18$ seen in the present study can be attributed to the different inclusion and exclusion criteria adopted in the present study.

In the present study, it was observed that prevalence of myopia and hyperopia significantly more in eyes with ptosis than in fellow normal eyes. This supports existing data reported by various studies showing a higher prevalence of refractive errors in ptotic eyes than in the eyes without ptosis. ${ }^{6,7,15}$ The higher frequency of refractive errors denote increase in ametropia with increase in severity of ptosis.

The present study showed that the frequency of myopia and hyperopia increases with increase in the severity of ptosis with $25 \%$ myopic eyes having moderate ptosis and $37.5 \%$ myopic eyes having severe ptosis. Similarly, $35.71 \%$ hyperopic eyes had moderate ptosis and $64.29 \%$ had severe ptosis.

In the present study, the prevalence of astigmatism was estimated by two different methods, refraction with cycloplegia and corneal topography. Significant refractive astigmatism was seen in eyes with ptosis as compared to normal fellow eyes. These findings correlated with the study by Ugurbas and Zilelioglu on corneal topography in patients with congenital ptosis. ${ }^{5}$ Similarly, study conducted by Huo $\mathrm{L}$ et al on form deprivation amblyopia in unilateral congenital ptosis found significantly high prevalence of astigmatism in eyes with ptosis as compared to normal fellow eyes. ${ }^{13}$ The prevalence of astigmatism in eyes with ptosis documented in the literature ranges from $8.9 \%$ as reported by Thapa $\mathrm{R}$ to $32.4 \%$ as reported by Hashemi $\mathrm{H}$ et al. ${ }^{7,16}$ However, the definition of astigmatism varies in different studies. Astigmatism has been considered significant if its magnitude is $\geq 0.5 \mathrm{D}$ while some has considered it significant if it is $\geq 1 \mathrm{D} .{ }^{10,11,17}$ Huo L et al, considered $>0.75 \mathrm{D}$ as astigmatism while Paik Ji-Sun et al defined amblyogenic astigmatism as $\leq 1.5 \mathrm{D}$ and found significantly more prevalence of refractive astigmatism $(47.76 \%)$ in eyes with ptosis. ${ }^{13,18}$ The different criteria used for defining astigmatism might be the reason for the higher prevalence of astigmatism in ptotic eyes seen in the present study. Similar findings were seen on comparison of astigmatism by corneal topography termed as Sim K astigmatism between eyes with and without ptosis.

The most common topographic pattern seen in ptotic eyes in this study was symmetric bow tie. The frequency of symmetrical bow tie pattern on corneal topography increased with increase in the severity of ptosis. The findings of corneal topographic patterns seen in the present study are in accordance with the study by Ugurbas and Zilelioglu on corneal topography in patients with congenital ptosis which concluded that the incidence of bow tie pattern was significantly more in eyes with ptosis..$^{5}$ In the present study, the higher prevalence of clinically significant astigmatism (both refractive and sim $\mathrm{K}$ astigmatism) in ptotic eyes was in accordance with the most common topographic pattern observed i.e. bow tie pattern. This study has shown that eyelid ptosis has a detrimental effect on corneal topography which was more asymmetrical and irregular as compared with normal 
fellow eyes ( 8 ptotic eyes had an irregular pattern as compared to 3 normal eyes).

The greater prevalence of Sim K astigmatism (57.83\%) than refractive astigmatism $(45.78 \%)$ seen in ptotic eyes in the present study could be because corneal topography could detect astigmatism before it could be detected clinically by refraction. The same finding was confirmed by observing the bow tie pattern in significantly more number of ptotic eyes than refractive astigmatism seen in eyes with ptosis.

It could thus be inferred that the detrimental effects of eyelid ptosis on the cornea and refractive status of the eye could be detected earlier with corneal topography.

\section{CONCLUSION}

Upper eyelid pressure in ptosis causes significant refractive and corneal topographic changes. The greater prevalence of $\operatorname{Sim} \mathrm{K}$ astigmatism (57.83\%) than refractive astigmatism $(45.78 \%)$ underlines the need of corneal topography in all cases to ensure timely detection of astigmatism and institution of proper corrective measures to prevent development of amblyopia.

Funding: No funding sources Conflict of interest: None declared

Ethical approval: The study was approved by the Institutional Ethics Committee

\section{REFERENCES}

1. Kostick DA, Bartley GB. Upper eyelid malpositions-congenital ptosis. In: Albert D, Miller J, Azar D, Blodi B. Albert and Jakobiec's Principles and Practice of Ophthalmology. 3rd ed. Philadelphia: WB Saunders; 2008:3395.

2. Beard C. Ptosis. 3rd ed. St. louis; 1981:41.

3. Shaw AJ, Collins MJ, Davis BA, Carney LG. Eyelid pressure and contact with the ocular surface. Invest Ophthalmol Vis Sci. 2010 Apr;51(4);1911-7.

4. Read SA, Collins MJ, Carney LG. The influence of eyelid morphology on normal corneal shape. Invest Ophthalmol Visual Sci. 2007Jan1;48(1):112-9.

5. Ugurbas SH, Zilelioglu G. Corneal topography in patients with congenital ptosis. Eye (Lond). 1999 Aug;13 (Pt 4):550-4.

6. PV NK, Kamala D. Refractive Errors in Congenital Ptosis-A Clinical Study. MRIMS. 2016;4(2).

7. Thapa R. Refractive error, strabismus and amblyopia in congenital ptosis. J Nepal Med Assoc. 2010;49(177):43-6.
8. CONGÉNITA EN. Comparative study of refractive errors in simple congenital myogenic ptosis and control children. Arch Soc Esp Oftalmol. 2008;83:601-6.

9. Bogan SJ, Waring GO, Ibrahim 0, Drews C, Curtis L. Classification of normal corneal topography based on computer-assisted videokeratography. Arch Ophthalmol. 1990;108:945-9.

10. Chen-Wei Pan, Tien-Yin Wong, Raghavan Lavanya, et al. Prevalence and Risk Factors for Refractive Errors in Indians: The Singapore Indian Eye Study (SINDI). Invest Ophthalmol Vis Sci. 2011;52(6):3166-73.

11. Dandona L, Dandona R, Naduvilath TJ, et al. Refractive errors in an urban population in Southern India: the Andhra Pradesh Eye Disease Study. Invest Ophthalmol Vis Sci. 1999;40:2810-8.

12. Bavishi AK, Patel CK. Blepharoptosis. Ind J Ophthalmol. 1982;30:503.

13. Huo L, Cui D, Yang X, Wan W, Liao R, Trier K, Zeng J. A retrospective study: form-deprivation myopia in unilateral congenital ptosis. Clin Exp Optometry. 2012 Jul;95(4):404-9.

14. Kumar DA, Agarwal A, Prakash G, Boptm NV, Packiyalakshmi S, Agarwal A. Effect of unilateral congenital ptosis on ocular higher order aberrations in children. Medical Hypothesis, Discovery and Innovation in Ophthalmol. 2013;2(3):86.

15. Nepal BP, Koirala S, Adhikary S, Sharma AK. Ocular morbidity in schoolchildren in Kathmandu. Brit J Ophthalmol. 2003 May 1;87(5):531-4.

16. Hashemi H, Khabazkhoob M, Emamian MH, Yekta A, Jafari A, Nabovati P, et al. The prevalence of ptosis in an Iranian adult population. J Curr Ophthalmol. 2016 Sep 1;28(3):142-5.

17. Griepentrog GJ, Diehl N, Mohney BG. Amblyopia in Childhood Eyelid Ptosis. Am J Ophthalmol. 2013;155(6):1125-8.

18. Paik JS, Kim SA, Park SH, Yang SW. Refractive error characteristics in patients with congenital blepharoptosis before and after ptosis repair surgery. BMC Ophthalmology. 2016 Oct 8;16(1):177.

Cite this article as: Vichare NV. Prevalence of refractive errors and corneal topographic changes in unilateral congenital ptosis vs the fellow eye: a clinical study. Int J Res Med Sci 2019;7:442-6. 